\title{
Association of increased morbidity with the occurrence of hyperglycemia in the immediate postoperative period after elective pediatric neurosurgery
}

\author{
Nazel Oliveira Filho, MD, MSc, ${ }^{1,3}$ Rodrigo L. Alves, MD, PhD, ${ }^{1,3}$ Adriano T. Fernandes, MD, MSc, ${ }^{1}$ \\ Fernanda S. P. Castro, MD, ${ }^{4}$ José Roberto Tude Melo, MD, PhD, ${ }^{2,5}$ and \\ Norma S. P. Módolo, MD, PhD6 \\ Departments of ${ }^{1}$ Anesthesiology and ${ }^{2}$ Pediatric Neurosurgery, Hospital São Rafael; ${ }^{3}$ Department of Anesthesiology, Hospital \\ Universitário Professor Edgar Santos, Salvador, Bahia; ${ }^{4 H o s p i t a l ~ B a r r a ~ D o r, ~ R i o ~ d e ~ J a n e i r o ; ~}{ }^{5}$ Hospital Universitário Professor \\ Edgar Santos, Salvador, Bahia; and ${ }^{6}$ Department of Anesthesiology, Faculdade Medicina de Botucatu, Universidade Estadual \\ Paulista, Botucatu, São Paulo, Brazil
}

\begin{abstract}
OBJECTIVE The acute elevation of blood glucose in perioperative pediatric patients subjected to cardiac surgery and in victims of head trauma is associated with higher rates of postoperative complications. Data on the occurrence of hyperglycemia and its association with unfavorable outcomes among patients who have undergone elective neurosurgery are scarce in the literature. This study aimed to determine whether the occurrence of hyperglycemia during the perioperative period of elective neurosurgery for the resection of tumors of the CNS in children is associated with increased morbidity. METHODS This retrospective cohort analysis included 105 children up to 12 years of age who underwent elective neurosurgery for resection of supratentorial and infratentorial CNS tumors between January 2005 and December 2010 at the São Rafael Hospital, a tertiary care medical center in Salvador, Brazil. Demographic data and intraoperative and postoperative information were collected from the medical records. Differences in blood glucose levels during the perioperative period were evaluated with nonparametric tests.
\end{abstract}

RESULTS The patients who developed postoperative complications exhibited higher blood glucose levels on admission to the intensive care unit (ICU) $(162.0 \pm 35.8 \mathrm{mg} / \mathrm{dl}$ vs $146.3 \pm 43.3 \mathrm{mg} / \mathrm{dl} ; p=0.016)$ and peak blood glucose levels on postoperative Day $1(171.9 \pm 30.2 \mathrm{mg} / \mathrm{dl}$ vs $156.1 \pm 43.2 \mathrm{mg} / \mathrm{dl} ; \mathrm{p}=0.008)$. Multivariate analysis showed that peak blood glucose levels on postoperative Day 1 were independently associated with a higher odds ratio for postoperative complication (OR 1.05). The occurrence of hyperglycemia (>150 mg/dl) upon admission to the ICU was associated with longer ICU $(p=0.003)$ and hospital $(p=0.001)$ stays.

CONCLUSIONS The occurrence of hyperglycemia during the postoperative period after elective pediatric neurosurgery for the resection of CNS tumors was associated with longer hospital and ICU stays. Postoperative complications were associated with higher blood glucose levels upon admission to the ICU and higher peak blood glucose on the first postoperative day.

http://thejns.org/doi/abs/10.3171/2015.9.PEDS1559

KEY WORDS hyperglycemia; pediatric; neurosurgery; central nervous system tumors; outcome; morbidity

$\mathrm{T}$ UMORS of the CNS are the main type of pediatric solid tumor and one of the leading causes of infant mortality in developed countries. ${ }^{7}$ The treatment for most pediatric CNS tumors involves resection, ${ }^{15}$ and although such surgery is necessary for the healing process of patients with CNS tumors, various risks are inherent to the procedure. The surgical stress triggers a neuroendocrine-metabolic response mechanism in response to the trauma, which includes an increase in hormones such as catecholamines, cortisol, and glucagon that, among other actions, causes an elevation in blood glucose to maintain the supply of energy substrate required for organ and tissue recovery. ${ }^{12}$ However, as in other clinical situations, the exacerbation of the physiological effects of the response mechanisms to trauma can cause organ damage on its own. ${ }^{1,10,12}$ Worse clinical outcomes were observed in pa-

ABBREVIATIONS ICU $=$ intensive care unit. 
tients, both adults and children, who had hyperglycemia in the perioperative period after various surgical procedures. ${ }^{6,13,19}$

Most studies in the pediatric population showing an association between morbidity and hyperglycemia were conducted in children who were the victims of a traumatic brain injury, underwent cardiac surgery, or were critically ill patients in intensive care units (ICUs). ${ }^{2,6,9,19}$ Little is known about this association in children with CNS tumors undergoing elective surgical procedures. Therefore, the aim of this study was to assess whether the occurrence of postoperative complications is associated with higher blood glucose levels in the intraoperative and early postoperative periods of elective neurosurgical resections of CNS tumors in pediatric patients.

\section{Methods}

After obtaining the approval of the medical research ethics committee of the São Rafael Hospital, we retrospectively studied all consecutive pediatric patients who underwent elective CNS tumor resection between January 2005 and December 2010 at the São Rafael Hospital in Salvador, Brazil. Perioperative variables were collected from medical records using a standardized form. The information collected during the preoperative period included the following: sex, age, body weight, associated diseases, corticosteroid use, and fasting glucose level.

All patients underwent arterial catheterization for continuous arterial blood pressure measurement and collection of blood samples. Surgery was performed under general balanced anesthesia with sevoflurane and intermittent doses of opioids and muscle-relaxant drugs. Normal saline was the main maintenance fluid used to provide basal metabolic requirements and replace losses from the surgical field. Fluids with glucose were not routinely given during the intraoperative period except in cases of hypoglycemia. Colloids were not used and blood products were administered according to the discretion of the attending anesthesiologist.

The following information was collected regarding the surgical and anesthetic procedure during the intraoperative period: duration of surgery, use of blood products, and administration of insulin, corticosteroids, or glucose solution. All blood glucose values obtained during the intraoperative period from blood samples that were collected from the vascular accesses (arterial or venous) were recorded and analyzed in an automated blood gas analyzer (ABL 700; Radiometer Medical).

In the immediate postoperative period, all patients were taken to the pediatric ICU where capillary blood glucose levels were measured with digital glucometers (glucose oxidase method) during the first 24 hours. Although there was not a specific protocol for blood glucose collection during the perioperative period at the institution studied, the measurements were usually conducted after an arterial puncture, at the end of surgery during the intraoperative period, on admission to the ICU, and at various times during the first postoperative day. Patients who did not have at least 2 blood glucose measurements during the intraoperative period and 4 blood glucose measurements during the postoperative period were excluded from the analyses. In the ICU the patients remained fasting for at least 8 hours with glucose administration at an infusion rate between 5 and $10 \mathrm{mg} / \mathrm{kg} / \mathrm{min}$ in the venous fluid replacement solution.

The blood glucose values were subdivided according to the perioperative moment as follows: preoperative baseline values (preoperative laboratory routine), the mean value of all intraoperative blood glucose, the value on admission to the ICU, the mean value of all measurements on the first postoperative day (excluding the value on admission to the ICU), and the peak blood glucose value during the postoperative period (highest value observed on the first postoperative day, with inclusion of the value on ICU admission). In our analysis, hyperglycemia was defined as values of $150 \mathrm{mg} / \mathrm{dl}$ or higher, and hypoglycemia was defined as values below $60 \mathrm{mg} / \mathrm{dl}$, according to the threshold values used in other studies. ${ }^{8,11,18}$

The occurrence of death and complications during the postoperative period was analyzed from the description of the patient's medical progress until hospital discharge. The types of complications were recorded according to predetermined definitions as follows: infection, namely a confirmed or suspected site of infection with antibiotic use; respiratory complications, the occurrence of which was based on the presence of radiological signs of pulmonary edema with a decrease in the $\mathrm{PaO}_{2} / \mathrm{FiO}_{2}$ ratio $(\leq 300)$; and neurological complications as follows: coma (persistent reduction of the level of consciousness for more than 48 hours, not attributable to sedation or residual effect of anesthesia, and characterized by incomplete awakening and impossibility of weaning from mechanical ventilation and removal of the orotracheal tube), seizure (episodes registered in the clinical records with or without need for specific medication), neurological deficit (previously absent cognitive, sensory, or motor disorder first observed after waking up from anesthesia or sedation and lasting more than 24 hours), and stroke (tomographic evidence of brain ischemia or bleeding).

Statistical comparisons among the differences of the mean blood glucose values during the perioperative period with the occurrence of postoperative complications and among the differences in the length of admission according to the blood glucose value on the ICU admission were made by using the Mann-Whitney U-test. The effect of the mean blood glucose values during the perioperative period with the occurrence of postoperative complication, which was adjusted for age, comorbidity, duration of surgery, and intraoperative administration of corticosteroid, glucose, and/or blood components, was estimated by odds ratio and corresponding 95\% confidence intervals resulting from binary logistic regression. Effects and differences were considered statistically significant if $p<0.05$. The statistical analyses were performed using the SPSS version 17.0 software (IBM Corp.).

\section{Results}

A total of 109 pediatric patients from 1 to 12 years of age underwent elective surgery for the resection of supratentorial and infratentorial CNS tumor during the study 
TABLE 1. Demographic data and anesthesia and surgical details from the intraoperative period

\begin{tabular}{lc}
\hline \multicolumn{1}{c}{ Variable } & Values $^{*}$ \\
\hline Age, yrs & $8(4-12)$ \\
\hline Weight, kg & $26(17-38)$ \\
\hline Sex, males & $58(55.2)$ \\
\hline Associated diseases & $13(12.4)$ \\
\hline Diabetes mellitus & $0(0)$ \\
\hline Duration of anesthesia, mins & $360(292-420)$ \\
\hline Duration of surgery, mins & $240(190-310)$ \\
\hline Intraop diuresis, ml & $450(300-762)$ \\
\hline Intraop transfusion & $19(18.1)$ \\
\hline Intraop hypoglycemia & $1(1.0)$ \\
\hline Intraop glucose administration & $11(10.5)$ \\
\hline Intraop insulin administration & $1(1.0)$ \\
\hline Intraop corticosteroid administration & $63(60.0)$ \\
\hline Preop use of corticosteroid & $21(20.0)$ \\
\hline Tumor location & \\
Supratentorial & $35(36)$ \\
Infratentorial & $70(64)$ \\
\hline Tumor histology & \\
Astrocytoma & $40(36.7)$ \\
Medulloblastoma & $8(7.3)$ \\
Craniopharyngioma & $6(5.5)$ \\
Ependymoma & $5(4.6)$ \\
Desmoplastic infantile ganglioglioma & $3(2.7)$ \\
Dysembryoplastic neuroepithelial tumor & $3(2.7)$ \\
Choroid plexus tumors & $2(1.8)$ \\
Others & $43(39.4)$ \\
\hline & \\
\hline &
\end{tabular}

* Data given as the median (interquartile range) or as number (\%).

period. Four patients were excluded because they had no record of perioperative blood glucose values, according to the adopted exclusion criteria. Of the remaining 105 patients, 58 were male and 47 were female. Their mean age was 8 years and their mean weight was $26 \mathrm{~kg}$ (Table 1).

The majority of tumors were infratentorial (64\%), and astrocytoma was the most frequent histological type observed in our population, followed by medulloblastoma, craniopharyngioma, and ependymoma, as seen in Table 1.

The surgical procedure had a mean length of 240 minutes, with an intraoperative transfusion of blood products in $18 \%$ of the cases (Table 1). In 11 patients, some type of glucose solution was used during the intraoperative period, and a single patient received intravenous insulin. In most patients (60\%), corticosteroid was administered during the intraoperative period at the request of the surgical team (Table 1).

Associated diseases were found in $12 \%$ of cases; however, no patient had a previous diagnosis of diabetes mellitus (Table 1). Thirty-one patients (29.5\%) developed postoperative complications, as shown in Table 2. Death occurred in 5 patients $(4.8 \%)$, and the main complication observed was infection, which occurred in 16 patients $(15.2 \%)$. None of the patients had hypoglycemia or the diagnosis of stroke (Table 2).
TABLE 2. Absolute and relative frequencies of death, combined events, prolonged mechanical ventilation ( $>48$ hours), and infectious and neurological complications during the postoperative period*

\begin{tabular}{lc}
\hline Postop Complications & No. of Patients (\%) \\
\hline Death & $5(4.8)$ \\
\hline Infectious complications & $16(15.2)$ \\
\hline Respiratory complication & $8(7.6)$ \\
\hline Seizure & $8(7.6)$ \\
\hline Coma & $5(4.8)$ \\
\hline Neurological deficit & $5(4.8)$ \\
\hline Stroke & $0(0)$ \\
\hline Hypoglycemia & $0(0)$ \\
\hline Combined events & $31(29.5)$ \\
\hline
\end{tabular}

* A "combined event" indicates death and/or complications of any type.

Only 2 patients had a fasting glucose value $\geq 150 \mathrm{mg} / \mathrm{dl}$ during the preoperative period, and 8 exhibited hyperglycemia during the intraoperative period (Table 3 ). However, during the postoperative period, $42.8 \%$ of subjects were hyperglycemic on admission to the ICU, and $52.4 \%$ of the cases had at least 1 value of $\geq 150 \mathrm{mg} / \mathrm{dl}$ in the first 24 hours of the postoperative period (Table 3 ).

Statistically significant differences were observed in the blood glucose levels between the groups of patients with or without complications for the time of ICU admission and for the peak blood glucose level on the first postoperative day, with higher values in patients in whom at least 1 of the morbidities was evaluated (Table 4). Multivariate analysis using the blood glucose levels on the perioperative period demonstrated that only the peak blood glucose level on the first postoperative day was independently associated with a higher odds ratio for postoperative complication when adjusted for age, comorbidity, duration of surgery, and intraoperative administration of corticosteroid, glucose and/or blood components (Table 5). Longer periods of hospitalization and longer stays in the ICU were also recorded among individuals who were hyperglycemic (blood glucose level $\geq 150 \mathrm{mg} / \mathrm{dl}$ ) at the time of ICU admission, as shown in Table 6.

\section{Discussion}

We observed that approximately $10 \%$ of patients had at least 1 blood glucose reading of $150 \mathrm{mg} / \mathrm{dl}$ or higher dur-

TABLE 3. Time of occurrence of a blood glucose level of $150 \mathrm{mg} / \mathrm{dl}$ or higher

\begin{tabular}{lc}
\hline \multicolumn{1}{c}{ Time Period } & No. of Patients $(\%)$ \\
\hline Preop & $2(1.9)$ \\
\hline Intraop & $8(7.6)$ \\
\hline Admission to the ICU & $45(42.8)$ \\
\hline Postop* $^{*}$ & $55(52.4)$ \\
\hline
\end{tabular}

${ }^{*}$ First 24 hours. 
TABLE 4. Blood glucose level according to occurrence of complications status

\begin{tabular}{lccc}
\hline $\begin{array}{c}\text { Time Period of } \\
\text { Blood Glucose } \\
\text { Level }\end{array}$ & \multicolumn{2}{c}{ Blood Glucose Level $(\mathrm{mg} / \mathrm{dl})^{*}$} & \\
\cline { 2 - 3 } & $\begin{array}{c}\text { Without } \\
\text { Complications }\end{array}$ & $\begin{array}{c}\text { With } \\
\text { Complications }\end{array}$ & $\begin{array}{c}\mathrm{p} \\
\text { Value }\end{array}$ \\
\hline Preop & $86.1 \pm 25.6$ & $87.3 \pm 17.2$ & 0.320 \\
\hline Intraop & $115.9 \pm 18.8$ & $126.0 \pm 51.5$ & 0.657 \\
\hline Admission to ICU & $146.3 \pm 43.3$ & $162.0 \pm 35.8$ & 0.016 \\
\hline Postop Day 1 & $137.8 \pm 25.6$ & $143.9 \pm 19.4$ & 0.136 \\
\hline Peak postop Day 1 & $156.1 \pm 43.2$ & $171.9 \pm 30.2$ & 0.008 \\
\hline
\end{tabular}

* Values are presented as the mean \pm SD.

ing the intraoperative period. Few studies have evaluated this issue in children who underwent neurosurgical procedures, and the studies that did examine the issue did not have a standardization of the blood glucose cutoff value for the definition of this event. Sharma et al. ${ }^{17}$ studied a retrospective cohort of children under 13 years of age who presented with a head trauma and underwent emergency neurosurgery. They found blood glucose levels of $200 \mathrm{mg} /$ $\mathrm{dl}$ or higher in $32 \%$ of the patients during the intraoperative period. The greater incidence of hyperglycemia, despite the higher threshold for its diagnosis, was most likely related to an earlier and more intense activation of the metabolic response at the time of the head trauma, compared with an elective procedure.

Approximately half of the individuals in our sample presented with hyperglycemia within the first 24 hours of the postoperative period. In a study of pediatric patients subjected to elective neurosurgery for various reasons, Mekitarian et al. ${ }^{11}$ also observed postoperative hyperglycemia (blood glucose level $\geq 150 \mathrm{mg} / \mathrm{dl}$ ) in $62.6 \%$ of the cases. Preissig and Rigby ${ }^{16}$ evaluated the occurrence of hyperglycemia (blood glucose level $>140 \mathrm{mg} / \mathrm{dl}$ ) in children in the ICU and observed that the neurosurgical patients exhibited the highest mean blood glucose level and the

TABLE 5. Logistic regression model for the occurrence of postoperative complications

\begin{tabular}{|c|c|c|c|}
\hline Variable & OR & $95 \% \mathrm{Cl}$ & $\mathrm{p}$ Value \\
\hline $\mathrm{Age}^{*}$ & 0.95 & $0.74-1.22$ & 0.72 \\
\hline Comorbidity & 2.40 & $0.13-11.1$ & 0.54 \\
\hline Intraop corticosteroid administration & 1.93 & $0.23-15.9$ & 0.53 \\
\hline Intraop glucose administration & 0.99 & $0.94-1.03$ & 0.57 \\
\hline Intraop transfusion & 0.58 & $0.18-1.40$ & 0.18 \\
\hline Duration of surgery* & 1.01 & $1.01-1.03$ & 0.04 \\
\hline Preop glucose level $^{*}$ & 1.00 & $0.95-1.06$ & 0.75 \\
\hline Average intraop glucose level ${ }^{*}$ & 0.96 & $0.94-1.03$ & 0.18 \\
\hline ICU admission glucose level* & 0.98 & $0.94-1.03$ & 0.69 \\
\hline Average glucose level on postop Day $1^{*}$ & 0.96 & $0.89-1.04$ & 0.38 \\
\hline Peak glucose level on postop Day $1^{*}$ & 1.06 & $1.01-1.13$ & 0.04 \\
\hline
\end{tabular}

TABLE 6. Length of ICU and hospital stay among patients who did or did not have a blood glucose level $\geq 150 \mathrm{mg} / \mathrm{dl}$ on admission to the ICU

\begin{tabular}{lccc}
\hline & \multicolumn{2}{c}{ Length of Stay in Days (IQR) } & \\
\cline { 2 - 3 } Location & $<150 \mathrm{mg} / \mathrm{dl}^{*}$ & $\geq 150 \mathrm{mg} / \mathrm{dl}^{*}$ & p Value \\
\hline ICU & $2.0(1.0-3.0)$ & $3.0(2.0-5.0)$ & 0.003 \\
\hline Hospital† & $5.0(4.0-8.0)$ & $8.0(5.0-15.7)$ & 0.001 \\
\hline * Blood glucose level on ICU admission. & & \\
$\dagger$ &
\end{tabular}

highest insulin requirement among all patients, both clinical and surgical.

Postoperative complications in patients who undergo resection of CNS tumors are common, even in elective procedures. Neervoort et al. ${ }^{14}$ evaluated a cohort of 121 patients under 18 years of age who underwent brain tumor resection (first surgery) and reported that $69 \%$ of patients experienced postoperative complications. The most frequent types included neurological complications (44\%), endocrinological disorders (22\%), and infectious complications (21\%). In our study, 29.5\% of patients developed postoperative complications, with infectious and neurological complications being the most frequent.

When comparing the mean blood glucose levels of patients at different times during the perioperative period, we observed higher blood glucose levels on ICU admission and a higher peak blood glucose level in the first 24 hours in individuals who developed postoperative complications. The peak blood glucose level on the first postoperative day was also independently associated with higher odds ratios for these complications. Similar observations were reported by other authors in the pediatric population in various scenarios, such as with head trauma ${ }^{3,14}$ and cardiac surgery. ${ }^{2,19}$

Another significant finding in our study was the association between hyperglycemia on admission to the ICU and an increased length of stay in the ICU and hospital. Hirshberg et al. ${ }^{8}$ assessed children who were hospitalized in the ICU for over 24 hours and also found an association between the occurrence of hyperglycemia (blood glucose $\geq 150 \mathrm{mg} / \mathrm{dl}$ ) during hospitalization in the ICU and a longer hospital stay. However, Mekitarian et al. ${ }^{11}$ found no association between hyperglycemia during the first 24-hour postoperative period of neurosurgery for various causes and longer ICU and hospital stays.

Several mechanisms have been proposed in the literature to justify the association between hyperglycemia and infection in different clinical and surgical scenarios, such as the reduction of free-radical production and the endothelial adhesion of neutrophils, a release of proinflammatory cytokines, the polymorphonuclear sequestration in peripheral tissues, and the decreased phagocytic ability of monocytes. ${ }^{1,5}$ Acute hyperglycemia also seems to have adverse effects on the CNS through an increased production of lactic acid and free radicals in the glial tissue, increased release of excitatory amino acids, increased intracellular calcium level, and mitochondrial and endothelial dysfunction. ${ }^{4}$ Although biologically plausible, in testing the hy- 
pothesis that hyperglycemia is a causative agent of greater postoperative morbidity, our study, similar to the majority of published studies on the topic, faces the inherent limitations of a retrospective study that does not adequately control for the necessary variables to determine causality between these 2 events.

\section{Conclusions}

The occurrence of hyperglycemia in the immediate postoperative period for children who underwent elective resection of CNS tumors is common and is associated with an increased risk for postoperative complications and an increased length of stay in the ICU and the hospital. In this study, it was not possible to define whether hyperglycemia is only a severity marker or if it is a causal factor in morbidity. Additional controlled prospective studies with a greater number of patients are needed to answer whether a more rigorous control of perioperative blood glucose levels in children subjected to elective neurosurgery could improve the prognosis of these patients.

\section{References}

1. Akhtar S, Barash PG, Inzucchi SE: Scientific principles and clinical implications of perioperative glucose regulation and control. Anesth Analg 110:478-497, 2010

2. Alves RL, Cerqueira MP, Kraychete NC, Campos GO, Martins MdeJ, Módolo NS: Perioperative blood glucose level and postoperative complications in pediatric cardiac surgery. Arq Bras Cardiol 97:372-379, 2011

3. Aş1lığlu N, Turna F, Paksu MS: Admission hyperglycemia is a reliable outcome predictor in children with severe traumatic brain injury. J Pediatr (Rio J) 87:325-328, 2011

4. Bilotta F, Giovannini F, Caramia R, Rosa G: Glycemia management in neurocritical care patients: a review. J Neurosurg Anesthesiol 21:2-9, 2009

5. Blondet JJ, Beilman GJ: Glycemic control and prevention of perioperative infection. Curr Opin Crit Care 13:421-427, 2007

6. Cochran A, Scaife ER, Hansen KW, Downey EC: Hyperglycemia and outcomes from pediatric traumatic brain injury. $\mathbf{J}$ Trauma 55:1035-1038, 2003

7. Grondin RT, Scott RM, Smith ER: Pediatric brain tumors. Adv Pediatr 56:249-269, 2009

8. Hirshberg E, Larsen G, Van Duker H: Alterations in glucose homeostasis in the pediatric intensive care unit: Hyperglycemia and glucose variability are associated with increased mortality and morbidity. Pediatr Crit Care Med 9:361-366, 2008

9. Klein GW, Hojsak JM, Schmeidler J, Rapaport R: Hyperglycemia and outcome in the pediatric intensive care unit. J Pediatr 153:379-384, 2008

10. Ljungqvist O, Nygren J, Soop M, Thorell A: Metabolic perioperative management: novel concepts. Curr Opin Crit Care 11:295-299, 2005
11. Mekitarian Filho E, Carvalho WB, Cavalheiro S, Horigoshi NK, Freddi NA, Vieira GK: Hyperglycemia and postoperative outcomes in pediatric neurosurgery. Clinics (Sao Paulo) 66: $1637-1640,2011$

12. McCowen KC, Malhotra A, Bistrian BR: Stress-induced hyperglycemia. Crit Care Clin 17:107-124, 2001

13. McGirt MJ, Woodworth GF, Brooke BS, Coon AL, Jain S, Buck D, et al: Hyperglycemia independently increases the risk of perioperative stroke, myocardial infarction, and death after carotid endarterectomy. Neurosurgery 58:1066-1073, 2006

14. Neervoort FW, Van Ouwerkerk WJ, Folkersma H, Kaspers GJ, Vandertop WP: Surgical morbidity and mortality of pediatric brain tumors: a single center audit. Childs Nerv Syst 26:1583-1592, 2010

15. Packer RJ, MacDonald T, Vezina G: Central nervous system tumors. Pediatr Clin North Am 55:121-145, xi, 2008

16. Preissig CM, Rigby MR: Pediatric critical illness hyperglycemia: risk factors associated with development and severity of hyperglycemia in critically ill children. J Pediatr 155:734-739, 2009

17. Sharma D, Jelacic J, Chennuri R, Chaiwat O, Chandler W, Vavilala MS: Incidence and risk factors for perioperative hyperglycemia in children with traumatic brain injury. Anesth Analg 108:81-89, 2009

18. Smith RL, Lin JC, Adelson PD, Kochanek PM, Fink EL, Wisniewski SR, et al: Relationship between hyperglycemia and outcome in children with severe traumatic brain injury. Pediatr Crit Care Med 13:85-91, 2012

19. Yates AR, Dyke PC II, Taeed R, Hoffman TM, Hayes J, Feltes TF, et al: Hyperglycemia is a marker for poor outcome in the postoperative pediatric cardiac patient. Pediatr Crit Care Med 7:351-355, 2006

\section{Disclosures}

The authors report no conflict of interest concerning the materials or methods used in this study or the findings specified in this paper.

\section{Author Contributions}

Conception and design: all authors. Acquisition of data: Filho, Alves, Castro, Módolo. Analysis and interpretation of data: Filho, Alves, Módolo. Drafting the article: Filho, Alves, Módolo. Critically revising the article: Filho, Alves, Fernandes, Melo, Módolo. Reviewed submitted version of manuscript: all authors. Approved the final version of the manuscript on behalf of all authors: Filho. Statistical analysis: Filho, Alves, Módolo. Administrative/technical/material support: Filho, Alves, Módolo. Study supervision: Filho, Alves, Melo, Módolo.

\section{Correspondence}

Nazel Oliveira Filho, Department of Anesthesiology, São Rafael Hospital, Rua Tenente Fernando Tuy, 62, Apt. 702, Pituba, Salvador, Bahia 41830498, Brazil. email: nazelfilho@ig.com.br. 